\title{
HYDRODYNAMICS AND HEAT TRANSFER AROUND A HORIZONTAL TUBE IMMERSED IN A GELDART B BUBBLING FLUIDIZED BED
}

\author{
PETER OSTERMEIER ${ }^{1}$, ANNELIES VANDERSICKEL ${ }^{1}$, MORITZ BECKER ${ }^{1}$, \\ STEPHAN GLEIS ${ }^{1}$ \& HARTMUT SPLIETHOFF ${ }^{1,2}$ \\ ${ }^{1}$ Institute for Energy Systems, Technical University of Munich, Germany. \\ ${ }^{2}$ Bavarian Center for Applied Energy Research (ZAE Bayern), Germany.
}

\begin{abstract}
In dense gas-solid fluidized beds the heat transfer to immersed objects is strongly coupled to the hydrodynamic behavior. The objective of this study is to experimentally and numerically assess the heat transfer coefficient around a horizontal tube in a Geldart B bubbling fluidized bed and derive a numerical-correlative approach for predicting the angular dependent heat transfer coefficient. The considered system consists of corundum as the solid bed material and air as the fluidization gas, entering the cylindrical geometry through a Tuyere nozzle distributor. Experimental data are obtained from a pilot scale test-rig with different tubular heat transfer probes and evaluated in a comprehensive uncertainty analysis. The resulting magnitude and angle dependent variations of the heat transfer coefficient at different superficial gas velocities are compared to three dimensional numerical simulations. The applied CFD model of the fluidized bed treats both gas and powder as Eulerian phases. The size distribution of the particles is described by two granular phases with corresponding mean diameters and a sphericity factor to account for their non-spherical shape. The fluid-solid interactions in this Multi Fluid Model are considered by incorporating the Kinetic Theory of Granular Flow and a sphericity-adapted drag model. The hydrodynamics at the tube surface, e.g. solid volume fraction, gas and particle velocities, are used for a novel numerical-correlative calculation of the angle dependent heat transfer coefficient between the bed material and the immersed tube. Special focus is set on depicting the particle contact time at the tube surface appropriately. The numerical results show the correct tendency of an increasing heat transfer coefficient with rising gas velocity and are partially in good agreement with the experimental observations.
\end{abstract}

Keywords: Eulerian approach, experimental investigation, fluidized bed, heat transfer coefficient, hydrodynamics, numerical simulation

\section{INTRODUCTION}

Gas-solid fluidized beds are employed in numerous industrial applications, such as gasification, combustion, synthesis reactions, cracking and various other chemical and metallurgical processes. The advantages of fluidized bed reactors compared to other gas-solid contacting methods are their superior mixing properties and hence virtually isothermal conditions, high heat and mass transfer rates between gas and particles, high heat transfer rates between the fluidized bed and immersed objects and their suitability for large-scale applications. Continuous automatically controlled operation can be achieved due to the smooth liquidlike flow of particles $[1,2]$. Despite their successful usage in industrial operations the flow dynamics in fluidized beds are not very well understood, because of the difficulty to obtain sufficient experimental data to quantify intrinsic phenomena. A proper understanding of the complex flow hydrodynamics is important for design, performance optimization and scale up of fluidized bed systems. This is even more important for the design of heat exchanger structures embedded within the fluidized bed, which requires an in depth understanding not only of the overall bed hydrodynamics, but in particular of internal particle flow patterns and velocities in the vicinity of the heat exchanger surface. For many industrial processes the heat transfer 
between the bed material and immersed objects is the limiting factor when dimensioning the apparatus.

In the literature several measurements of the heat transfer coefficient and the hydrodynamic behavior at heat exchanger surfaces immersed in fluidized beds have been performed. They consider the angle dependent heat transfer coefficient around horizontal tubes [3-13], the average heat transfer coefficient $[8,14-20]$, the effect of the surface shape [3, 21] or the influence of pipe arrangements $[8,9,22-25]$. It can be concluded that the average heat transfer depends on various specific experimental conditions, e.g. superficial gas velocity, bed voidage, material properties, bed geometry, tube diameter and position. For a relatively wide range of these conditions, correlations for calculating the average heat transfer coefficient can be derived from measurements. Three different approaches can be distinguished: packet models (Grewal and Saxena [15], Xavier and Davidson [26], Kunii and Levenspiel [1], Masoumifard et al. [27]), single particle models (Martin [28, 29]; Di Natale et al. [30]) and regime based models (Molerus et al. [31, 32]). They all have in common that they are only able to predict average heat transfer coefficients with the knowledge of global hydrodynamic values, which may not be sufficient e.g. for dimensioning heat exchanger bundles. Since internal hydrodynamics in the vicinity of heat exchanger surfaces can rarely be assessed, the correlation based calculation of local angle dependent heat transfer coefficients is much more difficult. Di Natale [33] tries to overcome this deficiency with velocity and angle dependent factors for the surface renewal frequency and the surface void fraction. A drawback of the model is its determination of the angle dependent hydrodynamic factors with additional experimental values and subsequent lack of general validity.

Besides correlative approaches, Computational Fluid Dynamics (CFD) can be used for predictions of the heat transfer coefficient. Existing numerical models [34-41] calculate the heat transfer coefficient based on the effective thermal conductivity of the emulsion, the volume fractions of gas and solids and the temperature gradient between surface and emulsion in the cells at the surface region [34, 42, 43]. With these approaches the strong coupling between hydrodynamics and heat transfer can be depicted and used for angle dependent investigations. The disadvantage is that the thermal boundary layer has to be resolved with cells smaller than the particle diameter [1] to capture the temperature gradient accurate enough. From a numerical point of view this contravenes the hydrodynamic cell size criterion [44] (cell size significantly larger than particle size) and additionally leads to small required time steps to fulfill the CFL criterion (Courant-Friedrichs-Lewy). In view of the large number of cells and the small time step, these simulations are performed on two-dimensional grids. The results often lack experimental validation or disagree with the experiments, which can be attributed to inaccurate prediction of the hydrodynamic behavior or the correlative calculation of thermal conductivity and porosity in the vicinity of the heat exchanger surface.

The objective of the presented study is to beneficially combine the correlative with the numerical approach, to obtain fast and more accurate predictions of the angle dependent heat transfer coefficient. The hydrodynamic behavior of the fluidized bed is calculated in an Eulerian-Eulerian formulation. Different particle sizes and their sphericity are incorporated by using a Multi Fluid Model (MFM) and a sphericity-adapted drag model. Fluid-solid interactions are further described by the Kinetic Theory of Granular Flow (KTGF). With the knowledge of the local hydrodynamic values of the solid volume fractions and the gas and particle velocity fields, the correlations for predicting the average heat transfer coefficient can be adapted to predict the local angle dependent heat transfer coefficient. The accurate resolution of the thermal boundary layer becomes obsolete, since the temperature gradient is not necessary in the correlative approach. Additionally, the hydrodynamics can be calculated on 
a much coarser grid, allowing three dimensional simulations of the fluidized bed geometry, including the nozzle configuration of the Tuyere distributor.

\section{EXPERIMENTAL APPARATUS AND DATA PROCESSING}

All experiments are performed in a cylindrical gas-solid bubbling fluidized bed containing Geldart B particles. Heat transfer coefficients are measured with two different tubular heat transfer probes and data are processed in a comprehensive error analysis, including numerical steady state thermal analysis of the probes in a Finite Element Method (FEM) framework.

\subsection{Experimental apparatus}

The cylindrical column (wall material acrylic glass) with a height of $450 \mathrm{~mm}$ and internal diameter of $140 \mathrm{~mm}$ is filled with corundum $\left(\mathrm{Al}_{2} \mathrm{O}_{3}\right)$ up to a height of $150 \mathrm{~mm}$. The fluidization air (superficial velocities from $0.10 \mathrm{~m} / \mathrm{s}$ to $0.30 \mathrm{~m} / \mathrm{s}$ ) leaves the nozzles radially and enters the column parallel to the bottom plate. The nozzles have a height of $2 \mathrm{~mm}$ and an outer diameter of $10 \mathrm{~mm}$. Further details on the test rig can be found in [45]. The heat transfer probes with a diameter of $20 \mathrm{~mm}$ are mounted at a height of $100 \mathrm{~mm}$. The experimental setup and the heat transfer probes are shown in Fig. 1, the material properties and experimental conditions in Table 1 .

The heating cartridges ( $\varnothing 4.0 \times 40 \mathrm{~mm}, 230 \mathrm{~V} / 70 \mathrm{~W}$ ) of the probes are supplied with constant power $(P=U I)$. By monitoring the temperature of the probe surface $T_{\text {sur }}$ and of the bed $T_{\text {bed }}$ with resistance thermometers (Pt100), the measured heat transfer coefficient $h_{\text {meas }}$ can be calculated with the surface area of the copper $A_{C u}$ according to eqn (1).

$$
h_{\text {meas }}=\frac{U I}{A_{C u}\left(T_{\text {surf }}-T_{\text {bed }}\right)}
$$
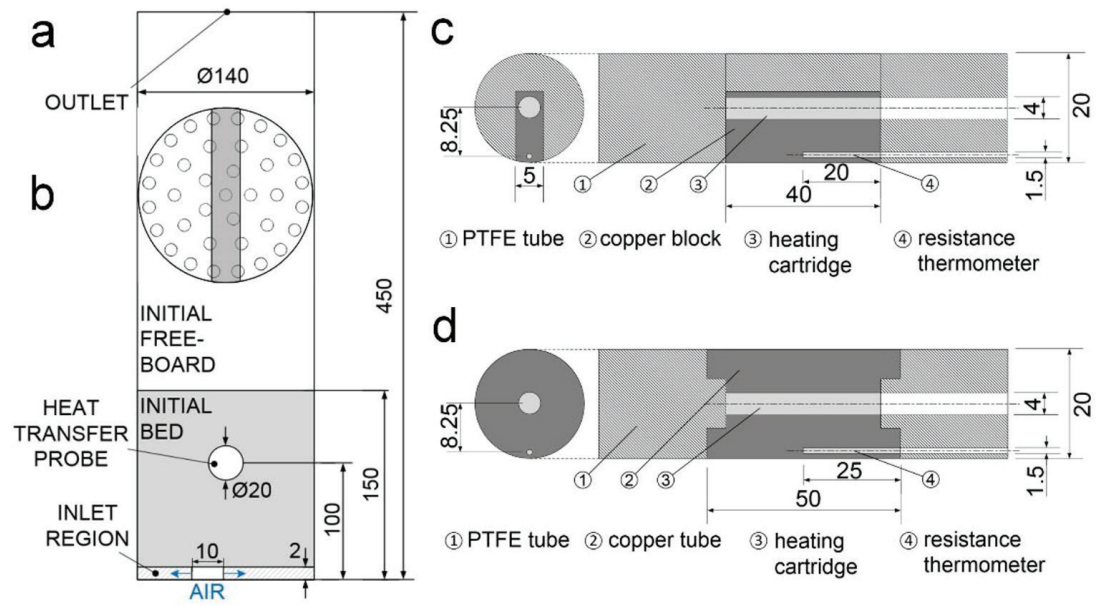

Figure 1: Experimental setup and heat transfer probes. (a) Dimensions of the test-rig; (b) Top view into the test-rig; (c) Circular segment heat transfer probe similar to [4]; (d) Overall perimeter heat transfer probe. 
Table 1: Material properties and experimental conditions.

\begin{tabular}{ll}
\hline Mean particle diameter & $197 \mu \mathrm{m} \in[153 \mu \mathrm{m}, 233 \mu \mathrm{m}]$ \\
Large particle mean diameter & $221 \mu \mathrm{m}$ \\
Small particle mean diameter & $174 \mu \mathrm{m}$ \\
Sphericity factor & 0.82 \\
Particle density & $3940 \mathrm{~kg} / \mathrm{m}^{3}$ \\
Bulk density & $1850 \mathrm{~kg} / \mathrm{m}^{3}$ \\
Solids conductivity & $25 \mathrm{~W} / \mathrm{mK}^{3}$ \\
Solids heat capacity & $778 \mathrm{~J} / \mathrm{kgK}$ \\
Solids volume fraction (loosely packed) & 0.47 (initial packing) \\
Solids volume fraction (densely packed) & $\approx 0.50$ (maximum packing limit) [46] \\
Minimum fluidization velocity & Experiment: $0.065 \mathrm{~m} / \mathrm{s}$ \\
& Correlation $[47]: 0.063 \mathrm{~m} / \mathrm{s}$ \\
Fluidization air superficial velocity & $($ large particle mean diameter) \\
& $0.10 \mathrm{~m} / \mathrm{s}, 0.15 \mathrm{~m} / \mathrm{s}, 0.20 \mathrm{~m} / \mathrm{s}, 0.25 \mathrm{~m} / \mathrm{s}$, \\
\hline
\end{tabular}

The Circular Segment Heat Transfer Probe (CSHT) [4] is able to measure the angle dependent heat transfer coefficient. The power converted to heat in the cartridge is expected to leave the probe almost exclusively through the copper block [4] with a surface angle of $28^{\circ}$ $\left(A_{C u}=28 / 360 \cdot \pi \cdot 20 \mathrm{~mm} \cdot 40 \mathrm{~mm}\right)$, because the thermal conductivity of copper $(400 \mathrm{~W} / \mathrm{mK})$ is much higher than the one of PTFE $(0.25 \mathrm{~W} / \mathrm{mK})$.

The Overall Perimeter Heat Transfer Probe (OPHT) measures the average heat transfer coefficient $\left(A_{C u}=\pi \cdot 20 \mathrm{~mm} \cdot 50 \mathrm{~mm}\right)$ over the entire perimeter of the probe and can be used to verify the values measured with the CSHT.

\subsection{Data processing}

The heat transfer coefficient measured with the OPHT was found to be significantly lower than the average value of the CSHT ( $n_{\theta}$ is the number of measured angles).

$$
h_{\text {meas }, \text { OPHT }}<\bar{h}_{\text {meas }, C S H T}=1 / n_{\theta} \cdot \sum_{\theta=0^{\circ}}^{360^{\circ}} h_{\text {meas }, C S H T}(\theta)
$$

Therefore the assumption of an almost perfect PTFE insulation [4] is not valid for the specific geometry of the CSHT used. For this reason the angle dependent heat transfer coefficient at segment $\theta, \quad h_{\text {meas }, \text { CSHT }}(\theta)=0.25\left[h_{\text {meas }, \text { CSHT }}(\theta-\beta)+2 h_{\text {meas }, \text { CSHT }}(\theta)+h_{\text {meas }, \text { CSHT }}(\theta+\beta)\right]$ with the neighboring segments $\theta \pm \beta$, is corrected to account for radial heat losses through the PTFE based on two dimensional steady state thermal FEM simulations in ANSYS Mechanical 16.0. Figure 2 shows the heat flux density and the temperature for the CSHT (left) and the OPHT (right) with a constant $h_{\text {meas }}=600 \mathrm{~W} / \mathrm{m}^{2} \mathrm{~K}$. Although in this representative example the heat flux density through the copper is much higher than through the PTFE in the CSHT, only $f_{\text {corr }, 1}(\theta)=55 \%$ of the integral heat flux is passing through the copper surface due to the large remaining PTFE surface area. Furthermore the simulated surface temperatures agree 


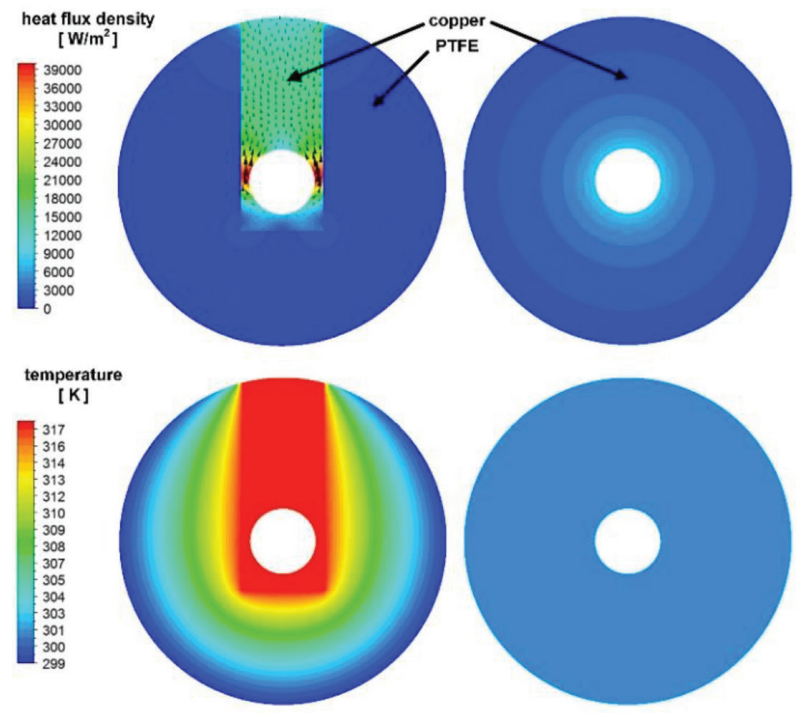

Figure 2: Heat flux density (top) and temperature distribution (bottom) in the CSHT (left) and OPHT (right).

with the measured only for the OPHT. In an iterative numerical process the heat transfer coefficient at segment $\theta$ of the CSHT is corrected in each of the $n_{\theta}$ segments according to eqn (3), until the simulated surface temperatures are in agreement with the measured ones.

$$
h_{\text {corr }, C S H T, j}(\theta)=f_{\text {corr }, j}(\theta) \cdot h_{\text {meas }, C S H T}(\theta)
$$

The corrected heat transfer coefficients of the CSHT are averaged and compared to the OPHT to validate the correction process. Compared to this systematic error the statistical error of the measurements is negligible and therefore not further considered herein.

\section{MATHEMATICAL MODELING}

The hydrodynamics of the fluidized bed are obtained from numerical simulations and combined with literature correlations to predict the heat transfer coefficient around the probe.

\subsection{Numerical simulation of hydrodynamics}

The three dimensional transient FVM simulations are carried out in ANSYS Fluent 16.0. The applied equations and nomenclature of the MFM can be found in Ostermeier et al. [45]. Further important data from the simulation setup are summarized in Table 2.

\subsection{Integration of heat transfer calculations}

From the aforementioned correlations for predicting the heat transfer coefficient, the modified approach according to Kunii and Levenspiel [1] yields the best results in combination with the numerical simulations applied in this work. The transient values for the solid volume 
Table 2: Excerpt from the simulation setup. Details in Ref. [45].

Time step size

Grid size at tube surface/inlet/bulk region

Fluid-solid interactions

Solid-solid interactions
$5 \cdot 10^{-4} \mathrm{~s}$

$0.875 \mathrm{~mm} / 1.75 \mathrm{~mm} / 3.5 \mathrm{~mm}$ (cut-cell approach) Huilin-Gidaspow [48] with sphericity factor $\psi$ Syamlal [49]

fraction $\alpha_{s}$, the gas velocity magnitude $\left|v_{g}\right|$ and the particle velocity magnitude $\left|\bar{v}_{s}\right|$ are obtained from the MFM. Via User-Defined Functions (UDFs) the instant numerical heat transfer coefficient $h_{\text {num }}$ is calculated according to eqn (4) and averaged over the respective surface $\left(30^{\circ}\right.$ segments, analogous to FEM simulation) and the simulation time $(\Delta t=6 \mathrm{~s})$. Radiation $h_{r}$ can be neglected since $T_{\text {suf }}<100^{\circ} \mathrm{C}$.

$$
h_{\text {num }}(\theta)=\left\{\begin{array}{r}
h_{r}+h_{b}(\theta) \approx h_{b}(\theta) \text { if }\left[1-\alpha_{s}(\theta)\right]>0.9 \\
h_{e}(\theta) \text { if }\left[1-\alpha_{s}(\theta)\right] \leq 0.9
\end{array}\right.
$$

The heat transfer of the bubbles $h_{b}$ is calculated with the equation of Baskakov et al. [3].

$$
h_{b}(\theta)=\frac{\lambda_{g}}{\overline{d_{s}}(\theta)}\left[0.009 \overline{A r}(\theta)^{0.5} \operatorname{Pr}^{0.33}\right]
$$

The heat transfer of the emulsion $h_{e}$ is calculated with the following equations [1]:

$$
\begin{gathered}
h_{e}(\theta)=\left[\frac{1}{2 \lambda_{e w}^{0}(\theta) / \overline{d_{s}}(\theta)+p_{1} c_{p, g} \rho_{g}\left|v_{g}(\theta)\right|}+\frac{1}{\left[\lambda_{e}^{0}(\theta) \rho_{s} c_{p, s} \alpha_{s}(\theta) / \pi t_{c}(\theta)\right]^{0.5}}\right]^{-1} \\
\lambda_{e w}^{0}(\theta)=\left[1-\alpha_{s}(\theta)\right] \lambda_{g}+\alpha_{s}(\theta) \lambda_{s}\left[\frac{1}{\phi_{w} \lambda_{s} / \lambda_{g}+1 / 3}\right] \\
\lambda_{e}^{0}(\theta)=\left[1-\alpha_{s}(\theta)\right] \lambda_{g}+\alpha_{s}(\theta) \lambda_{s}\left[\frac{1}{\phi \lambda_{s} / \lambda_{g}+2 / 3}\right]
\end{gathered}
$$

The conductivities of the mixture $\lambda_{e w}^{0}$ (wall) and $\lambda_{e}^{0}$ (bulk) in eqns (7) and (8) are calculated with the ratios of effective thickness of gas film around a contact point to particle diameter ( $\phi_{w}$ for contact between tube wall and particle and $\phi$ for contact between adjacent particles) according to eqns (9) and (10) and with the thermal conductivities of gas $\lambda_{g}$ and solids $\lambda_{s}$.

$$
\begin{gathered}
\phi_{w}=0.2495\left[\lambda_{s} / \lambda_{g}\right]^{-0.157} \\
\phi=0.1876\left[\lambda_{s} / \lambda_{g}\right]^{-0.170}
\end{gathered}
$$

For approximating the contact time $t_{c}$ in eqn (6), either the approach of Martin [28] in eqn (11) or the approach of Kim et al. [8] in eqn (12) can be used.

$$
t_{c}(\theta)=p_{2} \frac{\overline{d_{s}}(\theta)}{\left|\overline{v_{s}}(\theta)\right|}
$$




$$
t_{c}(\theta)=1.2\left[\frac{\overline{d_{s}}(\theta) g}{v_{m f}{ }^{2}\left(\left|v_{g}(\theta)\right| / v_{m f}-A\right)^{2}}\right]^{0.30}\left[\frac{\overline{d_{s}}(\theta)}{d_{\text {probe }}}\right]^{0.225}
$$

The parameters $p_{1}$ and $p_{2}$ in eqns (6) and (11) are chosen in a way that they predict the experimental data accurately enough and are in a physically reasonable range (see section 4). The values $\overline{d_{s}}(\theta), \overline{A r}(\theta)$ and $\overline{v_{s}}(\theta)$ are averaged over the volume fractions of the granular phases in the cells. A sampling interval of $\Delta t=6 \mathrm{~s}$ after fully developed fluidization yielded timeindependent mean time-averaged heat transfer coefficients.

\section{RESULTS AND DISCUSSION}

The experimental heat transfer coefficients from the OPHT and CSHT measurements are in good agreement after the iterative FEM correction and increase with the superficial air velocity (see Fig. 3 and Table 3). The FEM simulations can be terminated after the fifth iteration $(j=5)$ when the corrected heat transfer coefficient does not change significantly and the simulated surface temperature $T_{\text {sur }, F E M, 5}$ is in agreement with the measured $T_{\text {suf, meas }}$. The numerical heat transfer coefficients calculated with the contact time after Kim et al. with eqn (12) do not show the tendency of increasing average heat transfer coefficient $\bar{h}_{\text {num }}$ with rising gas velocity. However, when the contact time is calculated according to Martin with eqn (11), this tendency is predicted correctly. The simulations have been carried out with the parameters set to $p_{1}=0.01$ and $p_{2}=25$ and are discussed below in more detail.

The parameter $p_{1}=0.01$ used to weight the gas convection is smaller than in the original correlation $(0.05[1])$ for the average heat transfer, since the mean local velocity around the tube is about five times higher than the superficial velocity. The parameter $p_{2}=25$ leads to

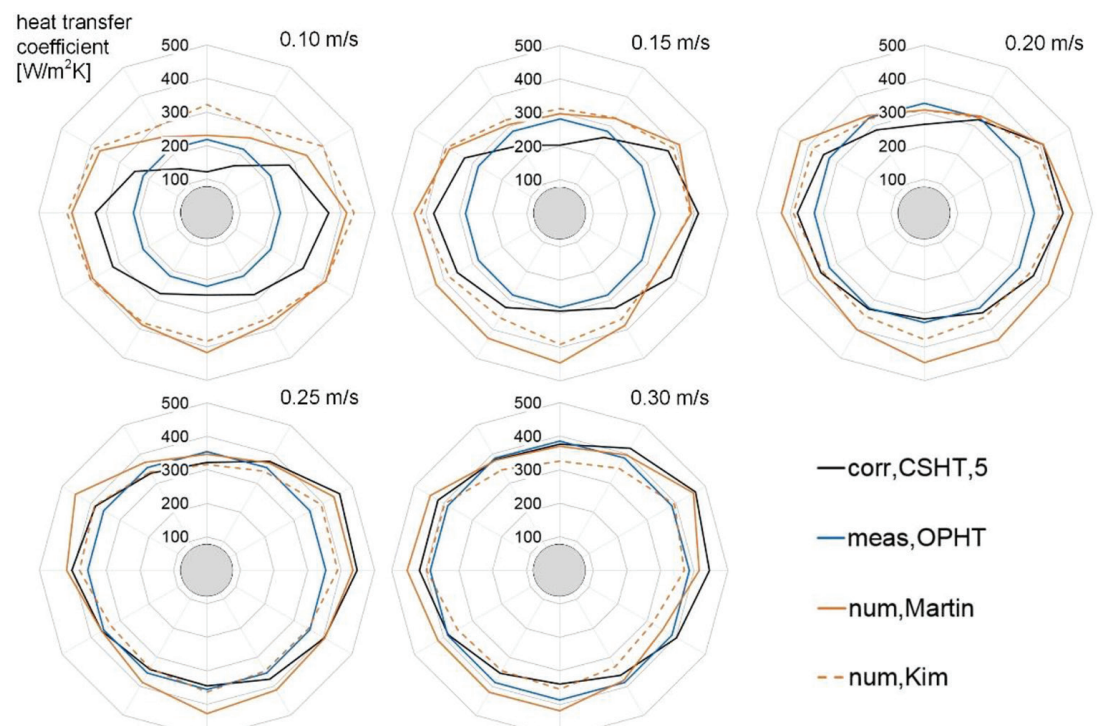

Figure 3: Time-averaged experimental and numerical mean values $(\Delta t=6 \mathrm{~s})$ of heat transfer coefficients for different superficial air velocities. 
Table 3: Summary of experimental and numerical results.

\begin{tabular}{llllll}
\hline & $0.10 \mathrm{~m} / \mathrm{s}$ & $0.15 \mathrm{~m} / \mathrm{s}$ & $0.20 \mathrm{~m} / \mathrm{s}$ & $0.25 \mathrm{~m} / \mathrm{s}$ & $0.30 \mathrm{~m} / \mathrm{s}$ \\
\hline$h_{\text {meas }, \text { OPHT }}\left[\mathrm{W} / \mathrm{m}^{2} \mathrm{~K}\right]$ & 219 & 281 & 327 & 355 & 386 \\
$\bar{h}_{\text {corr }, \text { CSHT }, 5}\left[\mathrm{~W} / \mathrm{m}^{2} \mathrm{~K}\right]$ & 260 & 322 & 345 & 379 & 397 \\
$\Delta \bar{T}_{\text {surf,meas }-F E M, 5}[\mathrm{~K}]$ & 0.50 & 0.18 & 0.17 & 0.19 & 0.10 \\
$\bar{h}_{\text {num }, \text { Martin }}\left[\mathrm{W} / \mathrm{m}^{2} \mathrm{~K}\right]$ & 355 & 381 & 397 & 402 & 409 \\
$\bar{h}_{\text {num }, \text { Kim }}\left[\mathrm{W} / \mathrm{m}^{2} \mathrm{~K}\right]$ & 374 & 364 & 361 & 356 & 357 \\
$\Delta \bar{t}_{c, \text { Martin-Kim }} / \bar{t}_{c, \text { Kim }}[-]$ & 0.32 & 0.01 & -0.21 & -0.32 & -0.32 \\
\hline
\end{tabular}

similar contact times as eqn (12) with tube area-weighted average values in the range of $0.12 \mathrm{~s}$ $(0.30 \mathrm{~m} / \mathrm{s})$ to $0.23 \mathrm{~s}(0.10 \mathrm{~m} / \mathrm{s})$, being in good agreement with the literature $[8,10]$.

For both the CSHT and the numerical obtained values, the heat transfer is high at the side walls of the tube and low at the top. Due to the strong coupling, this phenomenon can be explained by the hydrodynamic behavior. Figure 4 gives an insight into the fluidization process by showing the instant and time-averaged solids distribution and the time-averaged gas and solid velocity fields. Although the heat transfer coefficient around the horizontal tube is calculated with the instant hydrodynamic values, the time-averaged mean values depicted in Fig. 5 can be used to explain the profiles in Fig. 3. At the top of the probe $\left(120-180^{\circ}\right)$ the solid volume fraction is high and the solid velocity low, resulting in high contact times and low heat transfer to the emulsion, see eqns (6) and (11). A relatively high solid volume

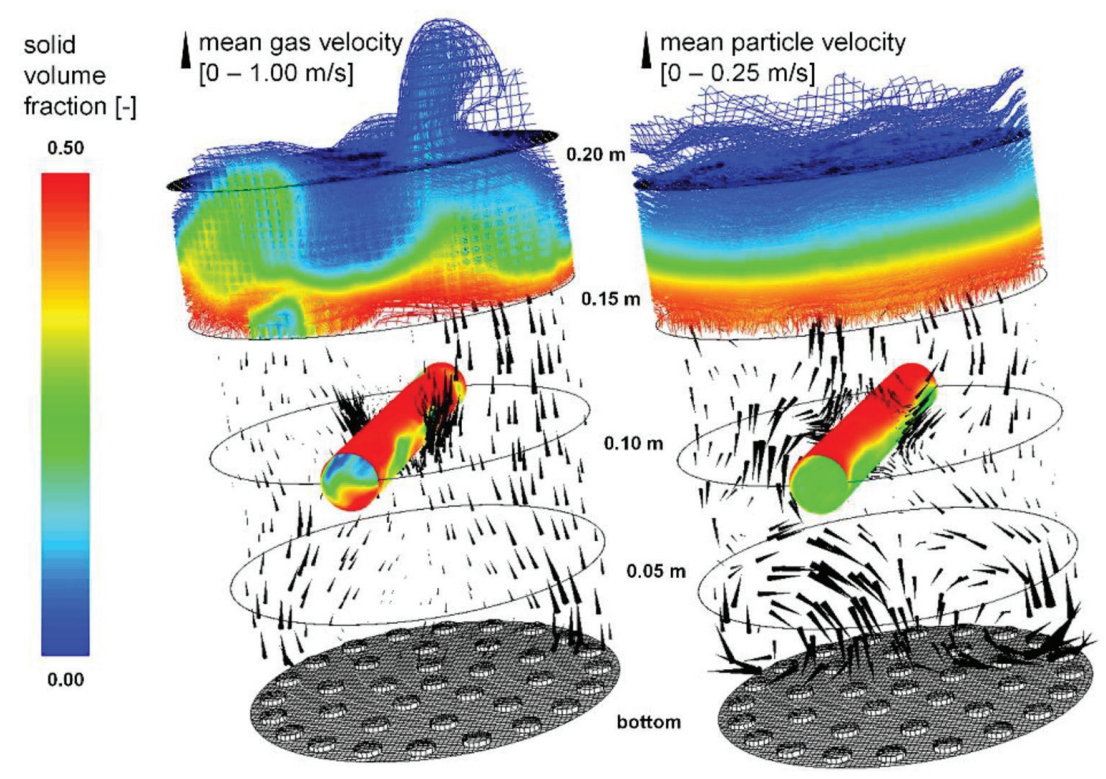

Figure 4: Contours of instant (left, $t=7 \mathrm{~s}$ ) and time-averaged (right, $\Delta t=6 \mathrm{~s}$ ) solid volume fraction with time-averaged gas (left) and time-averaged particle (right) velocity fields for a superficial air velocity of $0.20 \mathrm{~m} / \mathrm{s}$. 


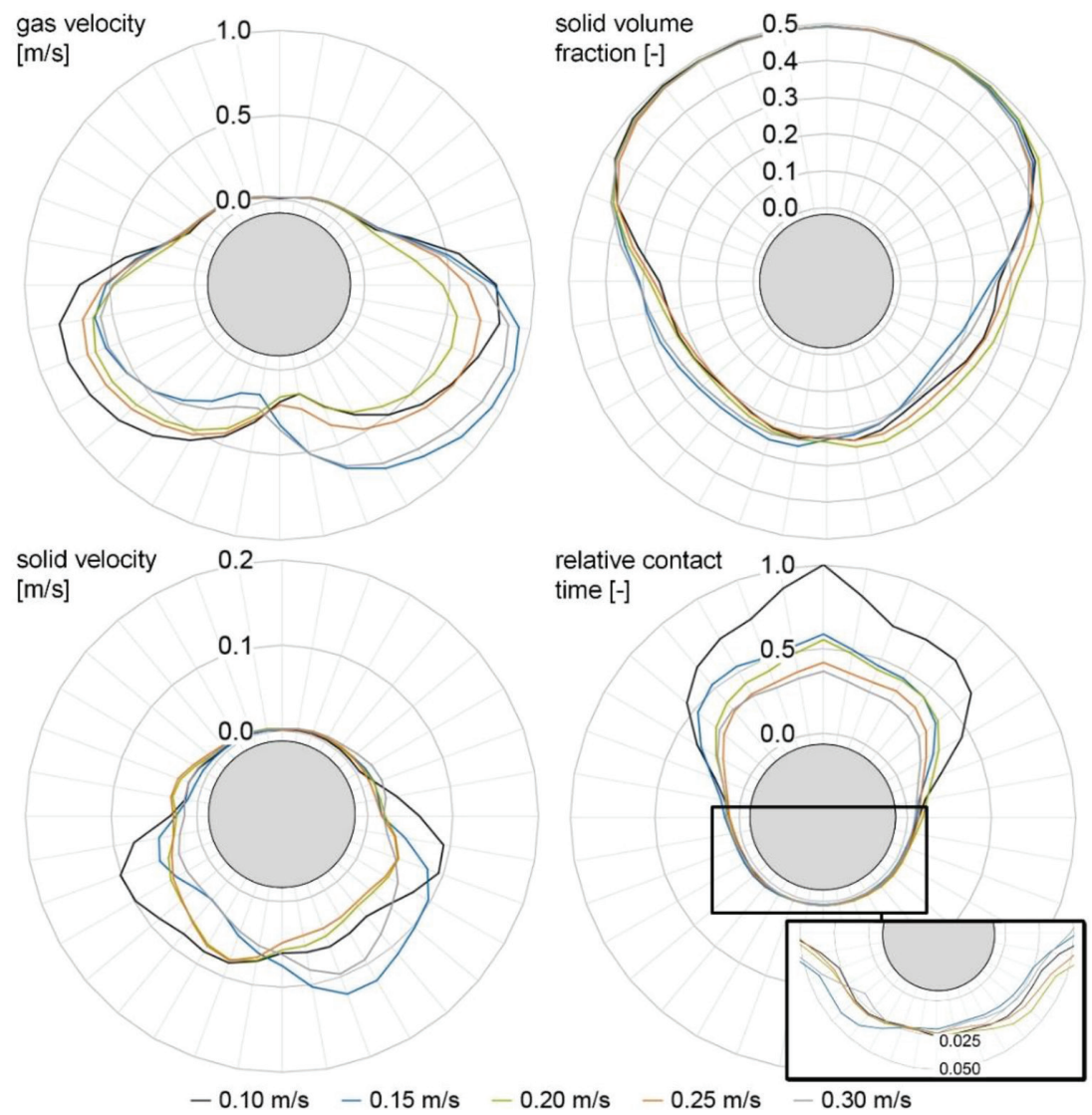

Figure 5: Time-averaged ( $\Delta t=6 \mathrm{~s}$ ) numerical MEAN values of gas velocity (top left), solid velocity (bottom left), solid volume fraction (top right) and relative contact time (bottom right) around the horizontal tube for different superficial air velocities.

fraction combined with high gas and particle velocities and hence small contact times leads to a very high heat transfer coefficient at the sides of the tube $\left(60-120^{\circ}\right)$. At the bottom $\left(0-60^{\circ}\right)$ the contact times are also small, but since there is less volume fraction the emulsion heat transfer is dominated by the gas velocities and volume fractions and the resulting thermal conductivities, see eqns (6) and (7). Furthermore the overall heat transfer coefficient at the bottom is decreased due to the increasing influence of the deteriorated heat transfer of the frequently impinging bubbles, see eqn (4).

While simulation and experiment are in good agreement at the side walls and on top of the tube, especially for high superficial air velocities, the simulation overpredicts the local heat transfer at the bottom of the tube, especially for low superficial air velocities. The simulations also overpredict the overall heat transfer. With increasing superficial air velocity the simulation using eqn (11) according to Martin follows the experimental trend on top of the tube (Fig. 3) due to the correct reduction of the contact time (Fig. 5).

At the bottom the numerical heat transfer coefficient does not increase like in the experiment, but rather stays at an almost constant high value. Since the hydrodynamic properties (Fig. 5) governing the correlation are also not depending on the superficial air velocity 
dominating the heat transfer in this region, the correlative-simulative approach in this form only possesses limited applicability when bubble and gas convection play a predominant role.

For this purpose, the hydrodynamics are further analyzed in Fig. 6, with respect to their applicability for correlative heat transfer prediction. The depicted area-weighted relative values for superficial velocity $i$ are calculated according to eqns (13) and (14), exemplarily for the contact time $t_{c}$.

$$
\begin{gathered}
t_{c, M E A N, \text { rel }, i}=t_{c, M E A N, i} / t_{c, M E A N, \max } \\
t_{c, R M S E, \text { rel }, i}=\left(t_{c, R M S E, i} / t_{c, R M S E, \text { max }}\right) /\left(t_{c, M E A N, i} / t_{c, \text { MEAN, } \max }\right)
\end{gathered}
$$

While the relative MEAN values illustrate the magnitude of the absolute instant values, the relative RMSE (root mean square error) values represent the magnitude of the fluctuation of the instant values. With increasing superficial air velocity the MEAN values of gas velocity/ solid velocity/solid volume fraction do not show the required tendency (increase/increase/ decrease) for the correlative calculations. Only the MEAN contact time decreases, governing the dominant heat transfer on the upper half of the tube and therefore increasing the MEAN heat transfer coefficient. When considering the RMSE values, they all exhibit the expected increase with rising superficial air velocity, indicating improved mixing behavior and consequently better applicability for correlative heat transfer calculations. For brevity, only the overall tube area-weighted values are depicted. The improved tendencies of the RMSE values over the MEAN values could also be observed for the angle dependent local values of the hydrodynamics. As a result, the next step is to adapt the respective terms of the correlation for combined numerical-correlative heat transfer predictions based on local fluctuation of hydrodynamic values (RMSE), representing the heat transfer governing mixing behavior around the tube.

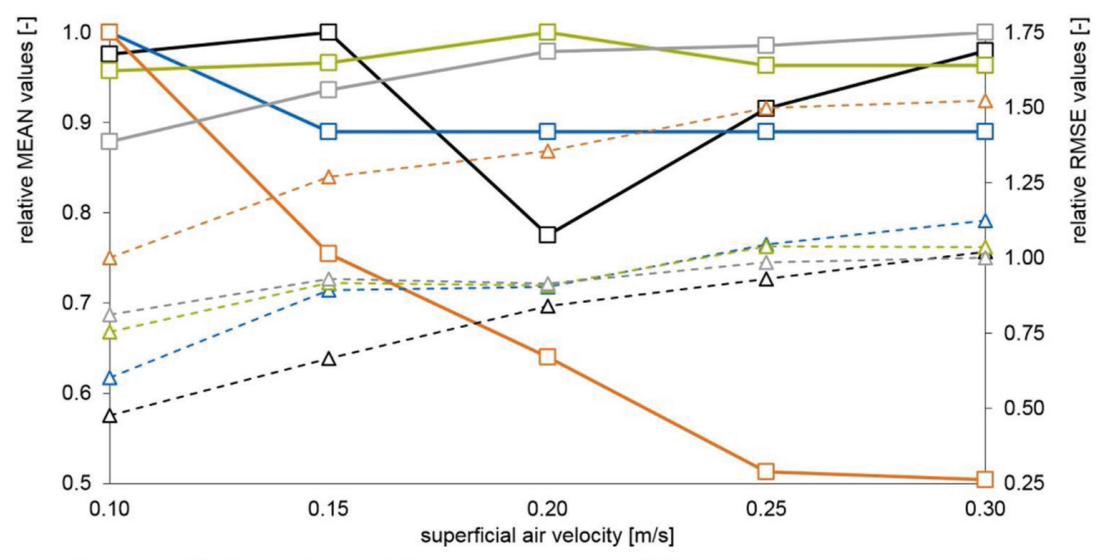

$-\square$-MEAN gas velocity - $\square$-MEAN solid velocity $-\square$-MEAN solid volume fraction $-\square-$ MEAN contact time $-\square-$ MEAN heat transfer coefficient $-\Delta$-RMSE gas velocity $-\Delta$-RSME solid velocity $-\triangle$-RMSE solid volume fraction $-\triangle$-RMSE contact time $-\triangle$-RMSE heat transfer coefficient

Figure 6: Time-averaged $(\Delta t=6 \mathrm{~s})$ and area-weighted (overall tube surface) numerical MEAN (solid lines) and RMSE (dashed lines) values of the relative heat transfer coefficient and the hydrodynamic values influencing its calculation. 


\section{CONCLUSIONS}

Heat transfer between a gas-solid fluidized bed and an immersed horizontal tube is investigated experimentally and numerically. The measured angle dependent heat transfer coefficients are corrected to account for radial heat losses through the probe in a 2D-FEM simulation and validated with the surface temperature and overall heat transfer measurements. The numerical-correlative calculated heat transfer coefficients are in good agreement with the experiment for higher superficial gas velocities in the upper region of the horizontal tube. This correlative approach therefore yields an effective method allowing three dimensional simulations of the fluidized bed geometry with heat transfer predictions, using only two substantiated fitting parameters. In the lower region and for superficial gas velocities close to minimum fluidization, the instant or mean hydrodynamics are not able to predict the heat transfer with high accuracy. A promising approach to overcome this drawback is the implementation of RMSE values in the correlation, representing the fluctuation of the hydrodynamics and therefore the mixing behavior of the fluidized bed.

\section{ACKNOWLEDGEMENT}

This research is part of the project 'Thermochemischer Energiespeicher für thermische Kraftwerke und industrielle Wärme' and is funded by the German Federal Ministry of Economic Affairs and Energy (BMWi) under the funding code 03ET7025 according to a decision of the German Federal Parliament.

\section{REFERENCES}

[1] Kunii, D. \& Levenspiel, O., Fluidization engineering, 2nd edn., Butterworth-Heinemann: Boston, 1991.

[2] Wen-Ching Yang, Handbook of fluidization and fluid-particle systems. Marcel Dekker: New York, 2003.

[3] Baskakov, A.P., Berg, B.V., Vitt, O.K., Filippovsky, N.F., Kirakosyan, V.A., Goldobin, J.M. \& Maskaev, V.K., Heat transfer to objects immersed in fluidized beds. Powder Technology, 8(5), pp. 273-282, 1973. https://doi.org/10.1016/0032-5910(73)80092-0

[4] Di Natale, F., Bareschino, P. \& Nigro, R., Heat transfer and void fraction profiles around a horizontal cylinder immersed in a bubbling fluidised bed. International Journal of Heat and Mass Transfer, 53(17-18), pp. 3525-3532, 2010. https://doi.org/10.1016/j.ijheatmasstransfer.2010.04.013

[5] George, A.H. \& Smalley, J.L., An instrumented cylinder for the measurement of instantaneous local heat flux in high temperature fluidized beds. International Journal of Heat and Mass Transfer, 34(12), pp. 3025-3036, 1991. https://doi.org/10.1016/0017-9310(91)90072-M

[6] George, A.H., Instantaneous local heat transfer coefficients and related frequency spectra for a horizontal cylinder in a high temperature fluidized bed. International Journal of Heat and Mass Transfer, 36(2), pp. 337-345, 1993. https://doi.org/10.1016/0017-9310(93)80009-J

[7] Khan, T. \& Turton, R., The measurement of instantaneous heat transfer coefficients around the circumference of a tube immersed in a high temperature fluidized bed. International Journal of Heat and Mass Transfer, 35(12), pp. 3397-3406, 1992. https://doi.org/10.1016/0017-9310(92)90226-I 
[8] Kim, S.W., Ahn, J.Y., Kim, S.D. \& Hyun Lee, D., Heat transfer and bubble characteristics in a fluidized bed with immersed horizontal tube bundle. International Journal of Heat and Mass Transfer, 46(3), pp. 399-409, 2003. https://doi.org/10.1016/S0017-9310(02)00296-X

[9] Olsson, S.E. \& Almstedt, A.E., Local instantaneous and time-averaged heat transfer in a pressurized fluidized bed with horizontal tubes: Influence of pressure, fluidization velocity and tube-bank geometry. Chemical Engineering Science, 50(20), pp. 32313245, 1995. https://doi.org/10.1016/0009-2509(95)00150-4

[10] Pence, D.V., Beasley, D.E. \& Figliola, R.S., Heat transfer and surface renewal dynamics in gas-fluidized beds. Journal of Heat Transfer, 116(4), p. 929, 1994. https://doi.org/10.1115/1.2911468

[11] Sunderesan, S.R. \& Clark, N.N., Local heat transfer coefficients on the circumference of a tube in a gas fluidized bed. International Journal of Multiphase Flow, 21(6), pp. 1003-1024, 1995. https://doi.org/10.1016/0301-9322(95)00020-X

[12] Kurosaki, Y., Ishiguro, H. \& Takahashi, K., Fluidization and heat-transfer characteristics around a horizontal heated circular cylinder immersed in a gas fluidized bed. International Journal of Heat and Mass Transfer, 31(2), pp. 349-358, 1988. https://doi.org/10.1016/0017-9310(88)90017-8

[13] Abid, B.A., Ali, J.M. \& Alzubaidi, A.A., Heat transfer in gas-solid fluidized bed with various heater inclinations. International Journal of Heat and Mass Transfer, 54(9-10), pp. 2228-2233, 2011.

https://doi.org/10.1016/j.ijheatmasstransfer.2010.12.028

[14] Friedman, J., Koundakjian, P., Naylor, D. \& Rosero, D., Heat transfer to small horizontal cylinders immersed in a fluidized bed. Journal of Heat Transfer, 128(10), p. 984, 2006. https://doi.org/10.1115/1.2345425

[15] Grewal, N.S. \& Saxena, S.C., Heat transfer between a horizontal tube and a gas-solid fluidized bed. International Journal of Heat and Mass Transfer, 23(11), pp. 1505-1519, 1980. https://doi.org/10.1016/0017-9310(80)90154-4

[16] Masoumifard, N., Mostoufi, N., Hamidi, A.-A. \& Sotudeh-Gharebagh, R., Investigation of heat transfer between a horizontal tube and gas-solid fluidized bed. International Journal of Heat and Fluid Flow, 29(5), pp. 1504-1511, 2008. https://doi.org/10.1016/j.ijheatfluidflow.2008.06.004

[17] Vreedenberg, H.A., Heat transfer between a fluidized bed and a horizontal tube. Chemical Engineering Science, 9(1), pp. 52-60, 1958. https://doi.org/10.1016/0009-2509(58)87007-4

[18] Grewal, N.S. \& Saxena, S.C., Maximum heat transfer coefficient between a horizontal tube and a gas-solid fluidized bed. Industrial \& Engineering Chemistry Process Design and Development, 20(1), pp. 108-116, 1981. https://doi.org/10.1021/i200012a017

[19] Pisters, K. \& Prakash, A., Investigations of axial and radial variations of heat transfer coefficient in bubbling fluidized bed with fast response probe. Powder Technology, 207(1-3), pp. 224-231, 2011.

https://doi.org/10.1016/j.powtec.2010.11.003 
[20] Stefanova, A., Bi, H.T., Lim, J.C. \& Grace, J.R., Local hydrodynamics and heat transfer in fluidized beds of different diameter. Powder Technology, 212(1), pp. 57-63, 2011. https://doi.org/10.1016/j.powtec.2011.04.026

[21] Di Natale, F., Lancia, A. \& Nigro, R., Surface-to-bed heat transfer in fluidised beds: effect of surface shape. Powder Technology, 174(3), pp. 75-81, 2007. https://doi.org/10.1016/j.powtec.2007.01.010

[22] George, S.E. \& Grace, J.R., Heat transfer to horizontal tubes in a pilot-scale fluidized bed. International Journal of Heat and Mass Transfer, 25(4), pp. 592-594, 1982. https://doi.org/10.1016/0017-9310(82)90063-1

[23] Hull, A.S., Chen, Z., Fritz, J.W. \& Agarwal, P.K., Influence of horizontal tube banks on the behavior of bubbling fluidized beds: 1. Bubble hydrodynamics. Powder Technology, 103(3), pp. 230-242, 1999.

https://doi.org/10.1016/S0032-5910(99)00021-2

[24] Hull, A.S., Chen, Z. \& Agarwal, P.K., Influence of horizontal tube banks on the behavior of bubbling fluidized beds: 2. Mixing of solids. Powder Technology, 111(3), pp. 192-199, 2000.

https://doi.org/10.1016/S0032-5910(99)00284-3

[25] Grewal, N.S. \& Saxena, S.C., Experimental studies of heat transfer between a bundle of horizontal tubes and a gas-solid fluidized bed of small particles. Industrial \& Engineering Chemistry Process Design and Development, 22(3), pp. 367-376, 1983. https://doi.org/10.1021/i200022a005

[26] Xavier A.M. \& Davidson J.F., Heat transfer in fluidized beds: Convective heat transfer in fluidized beds. In Davidson J.F., Clift R., Harrison D., Fluidization. 2nd edn., Academic Press: London, 1985.

[27] Masoumifard, N., Mostoufi, N. \& Sotudeh-Gharebagh, R., Prediction of the maximum heat transfer coefficient between a horizontal tube and gas-solid fluidized beds. Heat Transfer Engineering, 31(10), pp. 870-879, 2010. https://doi.org/10.1080/01457630903550275

[28] Martin, H., Heat transfer between gas fluidized beds of solid particles and the surfaces of immersed heat exchanger elements, part I. Chemical Engineering and Processing: Process Intensification, 18(3), pp. 157-169, 1984. https://doi.org/10.1016/0255-2701(84)80005-7

[29] Martin, H., Heat transfer between gas fluidized beds of solid particles and the surfaces of immersed heat exchanger elements, Part II. Chemical Engineering and Processing: Process Intensification, 18(4), pp. 199-223, 1984. https://doi.org/10.1016/0255-2701(84)87003-8

[30] Di Natale, F., Lancia, A. \& Nigro, R., A single particle model for surface-to-bed heat transfer in fluidized beds. Powder Technology, 187(1), pp. 68-78, 2008. https://doi.org/10.1016/j.powtec.2008.01.014

[31] Molerus, O., Burschka, A. \& Dietz, S., Particle migration at solid surfaces and heat transfer in bubbling fluidized beds-I. Particle migration measurement systems. Chemical Engineering Science, 50(5), pp. 871-877, 1995. https://doi.org/10.1016/0009-2509(94)00445-W

[32] Molerus, O., Burschka, A. \& Dietz, S., Particle migration at solid surfaces and heat transfer in bubbling fluidized beds-II. Prediction of heat transfer in bubbling fluidized beds. Chemical Engineering Science, 50(5), pp. 879-885, 1995.

https://doi.org/10.1016/0009-2509(94)00446-X 
[33] Di Natale, F. \& Nigro, R., A critical comparison between local heat and mass transfer coefficients of horizontal cylinders immersed in bubbling fluidised beds. International Journal of Heat and Mass Transfer, 55(25-26), pp. 8178-8183, 2012.

https://doi.org/10.1016/j.ijheatmasstransfer.2012.08.002

[34] Kuipers, J.A.M., Prins, W. \& Van Swaaij,W. P. M., Numerical calculation of wall-to-bed heat-transfer coefficients in gas-fluidized beds. AIChE Journal, 38(7), pp. 1079-1091, 1992.

https://doi.org/10.1002/aic.690380711

[35] Schmidt, A. \& Renz, U., Eulerian computation of heat transfer in fluidized beds. Chemical Engineering Science, 54(22), pp. 5515-5522, 1999.

https://doi.org/10.1016/S0009-2509(99)00298-5

[36] Schmidt, A. \& Renz, U., Numerical prediction of heat transfer between a bubbling fluidized bed and an immersed tube bundle. Heat and Mass Transfer, 41(3), pp. 257-270, 2005. https://doi.org/10.1007/s00231-004-0510-z

[37] Patil, D.J., Smit, J., van Sint Annaland, M. \& Kuipers, J.A.M., Wall-to-bed heat transfer in gas-solid bubbling fluidized beds. AIChE J., 52(1), pp. 58-74, 2006.

https://doi.org/10.1002/aic.10590

[38] Armstrong, L.M., Gu, S. \& Luo, K.H., Study of wall-to-bed heat transfer in a bubbling fluidised bed using the kinetic theory of granular flow. International Journal of Heat and Mass Transfer, 53(21-22), pp. 4949-4959, 2010.

https://doi.org/10.1016/j.ijheatmasstransfer.2010.05.047

[39] Armstrong, L.M., Gu, S. \& Luo, K.H., The influence of multiple tubes on the tube-to-bed heat transfer in a fluidised bed. International Journal of Multiphase Flow, 36(11-12), pp. 916-929, 2010.

https://doi.org/10.1016/j.ijmultiphaseflow.2010.07.004

[40] Yusuf, R., Halvorsen, B. \& Melaaen, M.C., Eulerian-Eulerian simulation of heat transfer between a gas-solid fluidized bed and an immersed tube-bank with horizontal tubes. Chemical Engineering Science, 66(8), pp. 1550-1564, 2011.

https://doi.org/10.1016/j.ces.2010.12.015

[41] Yusuf, R., Halvorsen, B. \& Melaaen, M.C., An experimental and computational study of wall to bed heat transfer in a bubbling gas-solid fluidized bed. International Journal of Multiphase Flow, 42, pp. 9-23, 2012.

https://doi.org/10.1016/j.ijmultiphaseflow.2012.01.003

[42] Zehner, P. \& Schlünder, E.U., Wärmeleitfähigkeit von Schüttungen bei mäßigen Temperaturen. Chemie Ingenieur Technik, 42(14), pp. 933-941, 1970 (in German).

https://doi.org/10.1002/cite.330421408

[43] Legawiec, B. \& Ziólkowski, D., Structure, voidage and effective thermal conductivity of solids within near-wall region of beds packed with spherical pellets in tubes. Chemical Engineering Science, 49(15), pp. 2513-2520, 1994.

https://doi.org/10.1016/0009-2509(94)E0070-7

[44] Enwald, H., Peirano, E. \& Almstedt, A.-E., Eulerian two-phase flow theory applied to fluidization. International Journal of Multiphase Flow, 22, pp. 21-66, 1996.

https://doi.org/10.1016/S0301-9322(96)90004-X 
[45] Ostermeier, P., Vandersickel, A., Gleis, S. \& Spliethoff, H., Three dimensional multi fluid modeling of Geldart B bubbling fluidized bed with complex inlet geometries. Powder Technology, 312, pp. 89-102, 2017. https://doi.org/10.1016/j.powtec.2017.02.015

[46] Fedors, R.F. \& Landel, R.F., An Empirical method of estimating the void fraction in mixtures of uniform particles of different size. Powder Technology, 23(2), pp. 225-231, 1979. https://doi.org/10.1016/0032-5910(79)87011-4

[47] Wen, C.Y. \& Yu, Y.H., A generalized method for predicting the minimum fluidization velocity. AIChE Journal, 12(3), pp. 610-612, 1966. https://doi.org/10.1002/aic.690120343

[48] Huilin, L. \& Gidaspow, D., Hydrodynamics of binary fluidization in a riser: CFD simulation using two granular temperatures. Chemical Engineering Science, 58(16), pp. 3777-3792, 2003. https://doi.org/10.1016/S0009-2509(03)00238-0

[49] Syamlal, M., The particle-particle drag term in a multiparticle model of fluidization. National Technical Information Service: Springfield, 1987. 